\title{
PAPERS
}

\section{Cell adhesion molecules in oesophageal epithelium}

\author{
H Dobson, M Pignatelli, D Hopwood, C D'Arrigo
}

\begin{abstract}
The distribution of a range of integrins, E-cadherin, and carcino-embryonic antigen (CEA) like molecules in normal human oesophageal epithelium was investigated immunohistochemically on frozen sections of endoscopic biopsy specimens. The integrin subunits $\alpha_{2}, \alpha_{3}$, $\alpha_{6}, \alpha_{v}, \beta_{1}$, and $\beta_{5}$ were expressed throughout the epithelium. There was strong expression of $\alpha_{2}, \alpha_{3}$, and $\beta_{1}$ subunits in the basal cell layer and for all the subunits studied the intensity of the staining decreased as cells moved towards the lumen. The heterodimer $\alpha_{v} \beta_{3}$ was expressed weakly in the basal aspect of the basal cell layer only. The CEA molecules were not present in the basal cells layer but there was weak expression in the prickle cell layer and strong positivity in the mature functional layer. E-cadherin was found throughout the epithelium but was weakly expressed at the basal aspect of the basal cells layer and showed strong positivity in the prickle cell and squamous cell layers. These results indicate that cellcell (E-cadherin, CEA) and cell-matrix (integrins) adhesion molecules show a well defined spatial pattern of immunoreactivity in the oesophageal mucosa and may play a part in the maintenance of normal tissue architecture and physiological homeostasis.

(Gut 1994; 35: 1343-1347)
\end{abstract}

Cell adhesion molecules are known to play a fundamental role in development and homeostasis of all tissues. ${ }^{1}$ The interaction of these molecules with their ligands is responsible for phenomena such as contact inhibition and density-dependent growth. ${ }^{2}$ It is known that in some diseases such as neoplasia there is a change in the expression and distribution of cell adhesion molecules. ${ }^{3-7}$ An understanding of the normal pattern of expression and distribution of these molecules is therefore necessary before the pathological conditions can be investigated.

There are no available studies on the distribution of oesophageal epithelial cell surface molecules but some work has been done on a number of other stratified squamous epithelia, such as skin, cervix, oral mucosa, and gingiva. ${ }^{348-10}$ These studies suggest that there are three major groups of cell adhesion molecules responsible for maintenance of such epithelia - integrins, carcino-embryonic antigen (CEA) like molecules (a group of cell surface receptors belonging to the larger immunoglobulin superfamily), and cadherins.

The integrins are a family of closely related transmembrane receptors for adhesion. ${ }^{11}$ On epithelia, integrins mediate the interactions of cells with the extracellular matrix and therefore play a major role in the regulation of epithelial cell differentiation. ${ }^{6711}$ Each integrin is a heterodimer of one $\alpha$ and one $\beta$ chain, and to date at least $14 \alpha$ chains and eight $\beta$ chains have been identified. ${ }^{12}$ Functionally, the integrins can be classified into groups according to their $\beta$ chain. Members of the $\beta_{1}$ integrin group are mainly involved in the adhesion of cells to structural glycoproteins such as the collagens, laminin, merosin, vitronectin, and fibronectin. ${ }^{11}$ Integrins are usually promiscuous in their ligand specificity and the same dimer often serves as receptor for a number of different molecules; on the other hand, different integrins recognise different parts of the same ligand. ${ }^{13-15}$

Cell-cell interactions in epithelia are thought to be mediated by E-cadherin molecules. ${ }^{16} 17$ Adhesions mediated by these molecules are $\mathrm{Ca}^{2+}$ dependent. ${ }^{17}$ There is some evidence suggesting that the cadherins have a fundamental role in the development and maintenance of tight junctions, desmosomes, and zonulae adherences, as demonstrated by the ability of specific monoclonal antibodies directed against E-cadherin to prevent the formation of any of these junctions. ${ }^{18-20}$

The CEA molecules differ from the other two groups in their binding specificity: they are able to bind in either a homophilic or heterophilic manner (that is either to each other or to another ligand), in contrast with the cadherins, which bind in a homophilic manner only and the integrins which are only capable of binding heterophilically. ${ }^{21}$ Previous studies suggest that only the more mature cells of stratified squamous epithelia express CEA on their membranes and their immunohistochemical visualisation has been used as a marker of differentiation in these epithelia. ${ }^{34}$ This observation, together with the reduction in the size and numbers of 
TABLE I Primary antibodies used in the study

\begin{tabular}{llllll}
\hline Antigen & Antibody & Type & Dilution & Species & Source \\
\hline$\alpha_{2}$ & HAS 3 & Monoclonal & $20 \mu \mathrm{g} / \mathrm{ml}$ & Mouse & Chemicon $^{36}$ \\
$\alpha_{3}$ & MAB 1952 & Monoclonal & $20 \mu \mathrm{g} / \mathrm{ml}$ & Mouse & Chemicon \\
$\alpha_{6}$ & MP4F10 & Monoclonal & Undiluted & Mouse & 23 \\
$\alpha_{\mathrm{v}}$ & $13 \mathrm{C} 2$ & Monoclonal & Undiluted & Mouse & 37 \\
$\beta_{1}$ & DH12 & Monoclonal & $20 \mu \mathrm{g} / \mathrm{ml}$ & Mouse & 38 \\
$\beta_{4}$ & $439-9 B$ & Monoclonal & $20 \mu \mathrm{g} / \mathrm{ml}$ & Mouse & 39 \\
$\beta_{5}$ & $\beta_{5}$ & Polyclonal & $20 \mu \mathrm{g} / \mathrm{ml}$ & Rabbit & M Hemler \\
$\alpha_{\mathrm{v}} \beta_{4}$ & 23 C6 & Monoclonal & Undiluted & Mouse & 37 \\
CEANCA & PR3B10 & Monoclonal & Undiluted & Mouse & 41 \\
CD15 & MC2 & Monoclonal & $20 \mu \mathrm{g} / \mathrm{ml}$ & Mouse & M Kerr \\
E-cadherin & HECD-1 & Monoclonal & $20 \mu \mathrm{g} / \mathrm{ml}$ & Mouse & 42 \\
\hline
\end{tabular}

$\mathrm{CEA}=$ carcino-embryonic antigen; $\mathrm{NCA}=$ non-specific cross reacting antigen.

desmosomes in the superficial layers of these epithelia, may suggest a role of CEA molecules in the maintenance of the functional layers (D Hopwood, unpublished work).

We have examined the expression and distribution of a number of cell adhesion molecules belonging to these three groups using immunohistochemical methods on frozen sections from endoscopic biopsy specimens of normal human oesophagus. We also discuss the possible functional interactions between the molecules studied, as there is now overwhelming evidence that the maintenance of normal tissue architecture is the result of multiple adhesion interactions rather than the function of a single molecule.

\section{Methods}

\section{SOURCE OF MATERIAL}

Biopsy specimens were obtained at endoscopy of patients with upper gastrointestinal symptoms. Patients gave informed written consent. The project was approved by the local ethical committee. Tissues were taken from areas of the oesophagus above the distal $5 \mathrm{~cm}$ that looked endoscopically normal. Four specimens were obtained from each of six patients. One specimen from each patient was processed and stained with haematoxylin and eosin as a histological control. The remaining specimens were frozen immediately after removal in liquid nitrogen-cooled isopentane. Frozen sections (each $9 \mu \mathrm{m}$ thick) from each patient were cut. The slides were fixed in cold acetone for 10 minutes at room temperature and washed in phosphate buffered saline (PBS) before staining. An indirect immunohistochemical technique was used for staining

TABLE II Staining intensity and distribution of adhesion molecules in human oesophageal epithelium

\begin{tabular}{|c|c|c|c|c|c|}
\hline \multirow[b]{2}{*}{ Antigen } & \multicolumn{2}{|c|}{ Stratum basale } & \multicolumn{2}{|c|}{ Stratum spinosum } & \multirow{2}{*}{$\begin{array}{l}\text { Stratum } \\
\text { squamosum }\end{array}$} \\
\hline & Basal & Apical & Lower half & Upper half & \\
\hline $\begin{array}{l}\alpha_{2} \\
\alpha_{3} \\
\alpha_{6} \\
\alpha_{v} \\
\beta_{1} \\
\beta_{4} \\
\beta_{5} \\
\alpha_{w} \beta_{2} \\
\text { CEA/NCA } \\
\text { CD15 } \\
\text { E-cadherin }\end{array}$ & $\begin{array}{l}+++ \\
+++ \\
++ \\
++ \\
+++ \\
+++ \\
++ \\
+1- \\
- \\
+ \\
+1-\end{array}$ & $\begin{array}{l}+++ \\
++ \\
+ \\
++ \\
+++ \\
++ \\
++ \\
+ \\
- \\
+\end{array}$ & $\begin{array}{l}+1- \\
++1+ \\
++ \\
+ \\
++ \\
+ \\
++ \\
+ \\
+1- \\
+1- \\
+++\end{array}$ & $\begin{array}{l}+ \\
+ \\
+ \\
+ \\
++1+ \\
+ \\
+ \\
+ \\
+++ \\
+++ \\
+++\end{array}$ & $\begin{array}{l}++ \\
+1- \\
- \\
- \\
+ \\
- \\
+1- \\
- \\
+++ \\
+++ \\
+++\end{array}$ \\
\hline
\end{tabular}

Staining is linear in all cases with the exception of MC2 which has a granular pattern. All staining is pericellular except for that seen with anti- $\beta_{5}$ antibodies which show a cytoplasmic distribution. using the avidin-biotin complex, as outlined below.

\section{ANTIBODIES AND REAGENTS}

PBS at $\mathrm{pH} 7 \cdot 25$ was prepared according to Dulbecco's formula. Table I summarises the details of the primary antibodies used; anti- $\alpha_{2}$ and anti- $\alpha_{3}$ antibodies were purchased from Chemicon International, London, UK. All antibodies used were in saturating concentrations, determined from previous studies. ${ }^{1422} 23$ The secondary antibodies were affinity isolated, biotinylated anti-mouse antibodies (raised in rabbit) or anti-rabbit antibodies (raised in swine, both from Dako, High Wycombe, UK). Both these secondary antibodies were used at a working dilution of $1: 300$ in PBS.

The avidin-biotin complex was obtained from Dako (High Wycombe, UK). Both the avidin and biotin solutions were separately diluted 1:100 in PBS, mixed and left to stand for 30 minutes before use. All incubations were carried out at room temperature.

\section{IMMUNOHISTOCHEMICAL STAINING}

To block non-specific binding of the secondary antibodies, $50 \mu \mathrm{l}$ of non-immune rabbit or swine serum were applied to each slide and incubated for 15 minutes. The slides were then drained and incubated for 30 minutes with $30 \mu \mathrm{l}$ of the primary antibody. The slides were drained again and rinsed quickly in PBS to prevent cross contamination during washing and then washed in PBS on a rotating platform three times (five minutes for each wash).

After washing, $50 \mu \mathrm{l}$ of the biotinylated secondary antibodies were applied and incubated for 30 minutes, after which time the slides were drained and washed three times in PBS (five minutes for each wash). Fifty $\mu l$ of the previously prepared avidin-biotin complex were then added to each slide and incubated for 30 minutes.

Antibody binding was visualised with a freshly prepared solution of $5 \mathrm{mg} \mathrm{ml}^{-1} 3,3^{\prime}-$ diamino benzidene (DAB, Sigma Chemicals, St Louis, MO, USA) in PBS. After filtration, the DAB solution was activated by the addition of cold $\mathrm{H}_{2} \mathrm{O}_{2}$ (to a final concentration of $0.03 \% \mathrm{v} / \mathrm{v}$ ) and $50 \mu \mathrm{l}$ of this mixture were immediately applied to each slide and incubated for five minutes. The DAB solution was removed by washing the slides in tap water (three washes, each for five minutes).

The slides were then counter stained with haematoxylin (20 seconds) followed by a brief rinse (20 seconds) in acid alcohol to restore the $\mathrm{pH}$. Finally, the slides were dehydrated in a graded alcohol series and mounted in DPX (British Drug Houses, Dagenham, Essex, UK).

\section{ASSESSMENT}

Each slide was randomly coded and subjectively assessed by three independent observers for intensity and distribution of the staining. 

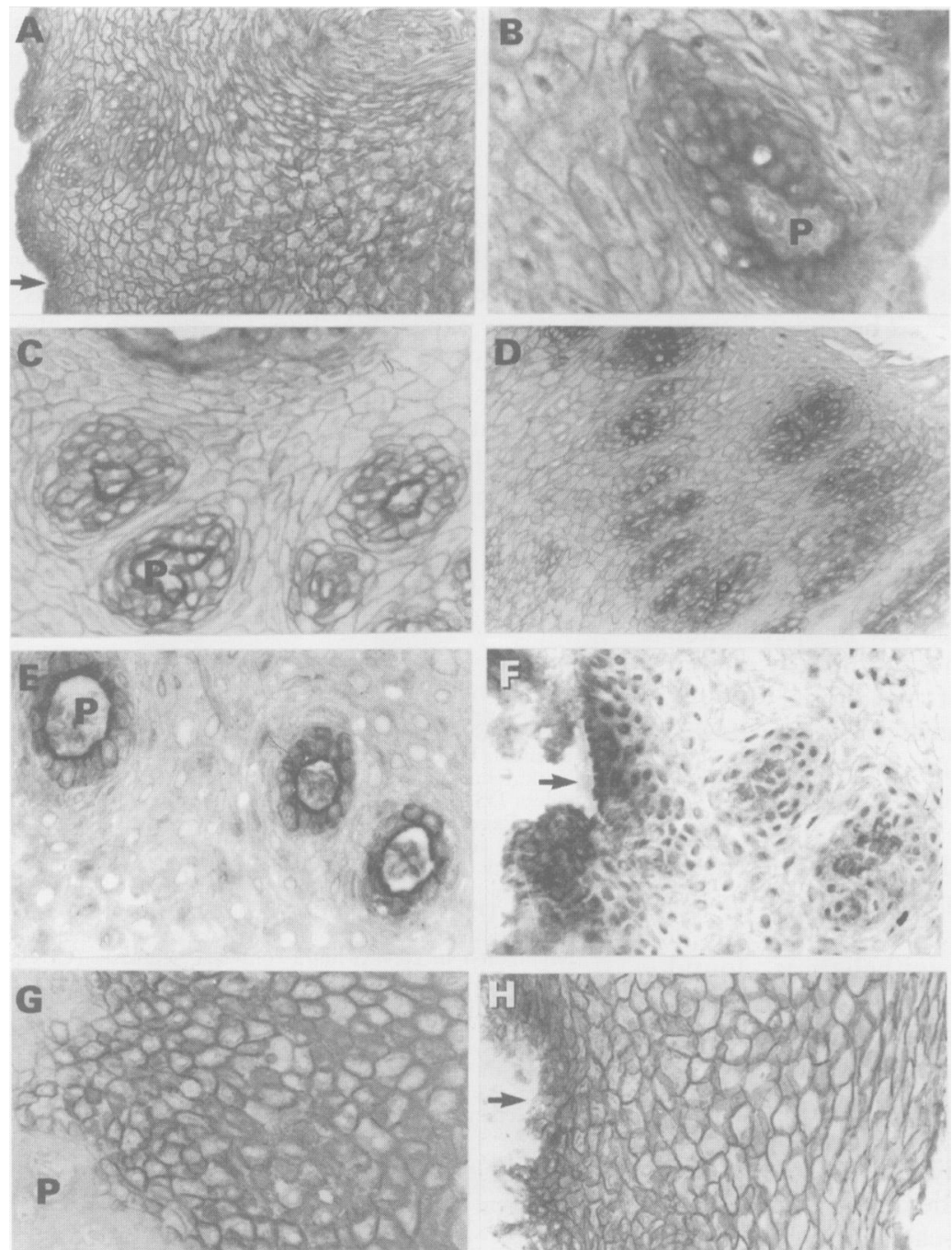

Photomicrographs of normal human oesophageal mucosa showing the pattern of distribution of adhesion molecules after immunoperoxidase staining and counterstaining with haematoxylin. Staining with anti- $\alpha_{2}(A)$, anti- $\alpha_{3}(B)$, anti- $\alpha_{6}(C)$, anti- $\beta_{1}(D)$, and anti- $\beta_{4}(E)$ shows greater intensity at the stratum basale, although for anti- $\alpha_{3}$ some staining is also present in the upper layers and for anti- $\alpha_{2}$ the stratum spinosum shows good staining intensity. Staining anti- $\alpha_{\mathrm{v}} \beta_{3}(F)$ is weak and only found at the stratum basale. Staining with anti-CEA (G) is present only in the upper half of the epithelium and staining with anti-E-cadherin $(H)$, although present throughout, is more noticeable in the stratum squamosum. Arrows indicate the basement membrane; $c=$ connective tissue; $p=$ connective tissue papilla. epithelium is restricted to the membranes of the suprabasal cells. This staining was very strong and uniform and little or no cytoplasmic staining was observed. In addition to the anti-CEA antibody, we also used $\mathrm{MC2}$, an antibody recognising CD15, a trisaccharide antigenic determinant (fucosyl-N-acetyllactosamine) associated with CEA. ${ }^{24}$ These results show a pattern of staining comparable with that shown for the anti-CEA, with staining only in the more mature suprabasal cells. Staining with the anti-CEA and the MC2 antibodies showed the presence of a gradient of CEA like molecules in the epithelium that parallel maturation, with the cells in the lower half of the stratum spinosum showing weak expression and the most mature squames strong positivity.

Staining with the E-cadherin antibody was strong, uniform, and largely restricted to the cell membranes. The distribution of this molecule in the epithelium showed an increasing gradient with maturation, but differently from the CEA like molecules, it was weakly present in the stratum basale, including the papillae.

With antibodies directed against the $\beta_{1}$ integrin subunit, the stain was restricted largely to the cell membranes. This chain is found throughout the epithelium, although the intensity of the stain was much greater in the stratum basale and showed a decreasing gradient of expression with maturation. A similar pattern of distribution was observed for the $\beta_{5}, \alpha_{3}$, and $\alpha_{v}$ subunits. The $\alpha_{6}$ subunit was also expressed by the epithelium and seemed to be distributed throughout the lower $50 \%$ of the epithelial thickness with the basal, prickle cell, and lower squamous layers showing weak staining and the more mature squames looking negative for this subunit. Mature squames seem to have very little or no expression of $\alpha_{3}, \alpha_{6}, \alpha_{v}, \beta_{1}, \beta_{4}, \beta_{5}$, and $\alpha_{v} \beta_{3}$. The $\alpha_{v} \beta_{3}$ dimer, known to be involved in the binding of cells to vitronectin, is only weakly present in the basal aspect of the basal cell layer. While for all the other adhesion molecules tested there was either a decreasing or an increasing gradient of expression with epithelial maturation, the distribution of the $\alpha_{2}$ subunit was peculiar in that it was strongly expressed in the basal layer, there was little expression in the stratum spinosum but then increased expression in the stratum squamosum. The staining for the $\beta_{4}$ subunit was solely restricted to the stratum basale with marked reaction towards the basal aspect of these cells. antibody, the avidin-biotin complexes or combination of these reagents were replaced by buffer and slides where the primary antibody used was an anti- $\alpha$-fetoprotein monoclonal antibody.

\section{Results}

The immunohistochemical and histological controls were negative. The results of this study are summarised in Table II. The anti-CEA antibody used cross reacted with non-specific cross reacting antigen (NCA); the results obtained for this antibody suggest that CEA distribution in normal oesophageal

\section{Discussion}

In this study we investigated the expression and distribution of three classes of adhesion molecules in the normal oesophageal squamous epithelium.

The presence and distribution of adhesion molecules in the normal human oesophagus are similar to those seen in stratified squamous epithelia of various regions of the oral mucosa. ${ }^{910}$ This is different from the epidermis, where integrin chains are found only in the most basal layer, whereas in the 
oesophagus these molecules are present throughout the thickness of the epithelium, although stronger staining is always seen in the basal cell layer. ${ }^{25-27}$ This distribution in the wet mucosae has been attributed to the higher cell turnover relative to the epidermis. ${ }^{9}$ It has been found that during wound healing or psoriasis, where epidermal turnover is increased, integrin chains are present also in the suprabasal regions. ${ }^{28}$ The oesophageal epithelium, like that of the oral mucosa, shows rapid turnover. ${ }^{29} 30$

The presence of integrins in the basal cell layer has been correlated with the presence of integrin ligands in the underlaying basement membrane but their expression in the suprabasal cells is unexplained, since no integrin ligands have been shown within the epithelium itself. This has led to speculation that integrins may bind homophilically or that these receptors are not functional in the suprabasal cells. ${ }^{7}$ We have recently shown, however, that integrins on suprabasal cells are functional in mediating cell adhesion. ${ }^{31}$

Immunohistochemical localisation and distribution of CD15 and CEA-like molecules in stratified squamous epithelia has been the subject of much study. 342432 CD15 is a trisaccharide that, in epithelia, is found predominantly on CEA-like molecules. ${ }^{24}$ All these reports indicate that these molecules are found only in the mature functional layers of the various epithelia and their use as markers for maturity has been proposed. ${ }^{4}$ Our results conform a previous study that looked at the distribution of CD15 in the oesophagus. ${ }^{3}$

The presence of E-cadherin has been reported in many different types of epithelia, including the stratified squamous epithelium of cervix..$^{33}$ In our study we can demonstrate E-cadherin throughout the oesophageal epithelium except in the basal aspect of the basal cell layer. It has been postulated that E-cadherin is involved in the maintenance of epithelial cohesiveness by mediating cell to cell adhesion. ${ }^{16} 17$

The oesophageal epithelium, like other stratifying squamous epithelia, has an important mechanical barrier function. This probably relies on strong cell-basement membrane and cell-cell adhesion. On the other hand, the maturation of the epithelium culminates in the shedding, within the lumen, of the most mature cells and this could not be possible without a reduction in cell-cell adhesion. Clearly, adhesion within the epithelium must be modulated. An indication that this is indeed the case can be derived from the topographical distribution of adhesion molecules. The $\alpha_{3}, \alpha_{v}$, $\beta_{1}$ and $\beta_{5}$ subunits, for instance, seem to be present in a gradient of decreasing intensity as cells move closer to the lumen. We could predict that when the number of these molecules present on the cell surface decreased below a certain threshold, cell-cell adhesion would be impaired and shedding of the epithelial cells would occur. However, other adhesion molecules are present in increasing rather than decreasing gradients, such as E-cadherin and CEA. It is interesting to note that the adhesive function of molecules such as E-cadherin can be modulated from within the cell by small molecules such as the catenins. ${ }^{34} 35$ Therefore the presence of large amounts of E-cadherin on the surface of mature oesophageal epithelial cells should not be interpreted as an indication of strong cell-cell adhesion, since these molecules may not be functional in the most superficial cells.

In this paper we have shown that the distribution of cell adhesion molecules in the normal oesophageal epithelium follows well defined patterns and we believe that these molecules have a pivotal role in the maintenance of mechanical barrier and homeostasis.

This work was funded in part by a Research Grant from the Scottish Office Home and Health Department.

1 Hynes RO, Lander AD. Contact and adhesive specificities in the associations, migrations and targeting of cells and axons. Cell 1992; 68: 303-22.

2 Rakic P. Contact regulation of neuronal migration. In: Edelman GM, Thiery J-P, eds. The cell in contact. New York: John Wiley and Sons, 1985:

3 Sanders DSA, Kerr MA, Hopwood D, Coghill G, Milne GA. Expression of the 3-fucosyl N-acetyllactosamine (CD15) antigen in normal, metaplastic, dysplastic and neoplastic squamous epithelia. $f$ Pathol 1988; 154: 255-62.

4 Sanders DSA, Kerr MA, Hopwood D, Coghill G Expression of the CD15 antigen is a marker of cellular differentiation in cervical intra-epithelial neoplasia (CIN). f Pathol 1988; 155: 207-12.

5 Dedhar S. Integrins and tumor invasion. Bio Essays 1990; 12: 583-90.

6 Del Buono R, Pignatelli M, Bodmer WF, Wright NA. The role of the arginine-gycine-aspartic acid-directed cellular binding to type I collagen and rat mesenchymal cells in colorectal tumour differentiation. Differentiation 1991; 46: 97-103.

7 Hall PA, Coates P, Lemoine MR, Horton MA Characterization of integrin chains in normal and neoplastic human pancreas. F Pathol 1991; 165: 33-41.

8 Carter WG, Wayner EA, Bouchard TS, Kaur P. The role of integrins $\alpha 2 \beta 1$ and $\alpha 3 \beta 1$ in cell-cell and cell-substrate integrins $\alpha 2 \beta 1$ and $\alpha 3 \beta 1$ in cell-cell and cell-substrate adhesion of

9 Jones J, Sugiyama M, Watt FM, Speight PM. Integrin expression in normal, hyperplastic, dysplastic and malignant oral epithelium. F Pathol 1993; 169: 235-43.

0 Hormia H, Ylanne J, Virtanen I. Expression of integrins in human gingiva. $\mathcal{F}$ Dent Res 1990; 69: 1817-23.

11 Hynes RO. Integrins: a family of cell surface receptors. Cell 1987; 48: $549-54$.

12 Humphries MJ. The molecular basis and specificity of integrin ligand interactions. 7 Cell Sci 1990; 97: 585-92.

13 Hynes RO. Integrins: versatility, modulation and signalling in cell adhesion. Cell 1992; 69: 11-25.

14 Stamp GWH, Pignatelli M. Distribution of $\beta_{1}, \alpha_{1}, \alpha_{2}$ nd $\alpha_{3}$ integrin chains in basal cell circinomas. $₹$ Pathol 1991 ;
int 163: 307-13.

15 Pignatelli $M$, Smith MEF, Bodmer WF. Low expression of collagen receptors in moderate and poorly differentiated colorectal adenocarcinomas. Br f Cancer 1990; 61: $636-8$

16 Takeichi $M$. Functional correlation between cell adhesive properties and some cell surface proteins. 7 Cell Biol 1977 75: 464-74.

17 Takeichi M. Cadherins: a molecular family important in selective cell-cell adhesion. Ann Rev Biochem 1990; 59: 237-52.

18 Behrens J, Birchmeier W, Goodman SL, Imhof BA Dissociation of Madin-Darby canine kidney epithelial cells by the monoclonal antibody anti-arc-1: mechanistic cells by the monoclonal antibody anti-arc-1: mechanistic uvomorulin. $\mathcal{F}$ Cell Biol 1985; 101: 1307-15.

19 Gumbiner B, Simons K. A functional assay for proteins involved in establishing an epithelial occluding barrier: identification of an uvomorulin-like polypeptide. $\mathcal{F} \mathrm{Cell}$ Biol 1986; 102: 457-68.

20 Griepp EB, Dolan WJ, Robbins ES, Sabatini DD Participation of plasma membrane proteins in the formation of tight junctions by cultured epithelial cells. $\mathcal{f} \mathrm{Cell}$ Biol 1983; 96: 693-702.

21 Williams AF, Barclay AN. The immunoglobulin superfamily - domains for cell surface recognition. Annu Rev Immunol 1988; 6: 381-405.

22 Pignatelli M, Liu D, Nasim MM, Stamp GWH, Hirano S, Takeichi M. Morphoregulatory activities of E-cadherin and beta-1 integrins in colorectal tumour cells. $B r \mathcal{J}$ Cancer 1992; 66: 629-34

23 Pignatelli M, Cardillo MR Hanby A, Stamp GWH. Integrins and their accessory adhesion molecules in mammary carcinomas. Human Pathol 1992; 23: 1159-66. 
24 Stocks SC, Sanders DSA, Hopwood D, Kerr MA. Expression of carcinoembryonic antigen (CEA) related glycoproteins and the Lewis carbohydrate antigen on nor$\mathrm{mal}$ and inflamed oesophageal squamous mucosa. $\mathcal{f}$ Pathol 1993 (in press).

25 Peltonen J, Larjava H, Jaakkola S, Gralnick H, Akijama SK, Yamada SS, et al. Localization of integrin receptors for fibronectin collagen and laminin in human skin. Variable expression in basal and squamous cell carcinomas. $\mathcal{F}$ Clin expression in basal and squan
Invest 1989; 84: 1916-23.

26 Klein CE, Steinmayer T, Mattes JM, Kaufman R, Weber L. Integrins of normal human epidermis: differential expression, synthesis and molecular structure. $\mathrm{Br} F$ Dermato 1990; 123: 171-8.

27 De Stropper B, Van Der Schueren B, Jaspers M, Saison M, Spaepen M, Van Leuven F, et al. Distribution of the $\beta 1$ subgroup of the integrins in human cells and tissues. f Histochem Cytochem 1989; 37: 299-307.

28 Hertle MD, Kubler M-D, Leigh IM, Watt FM. Abberant integrin expression during epidermal wound healing and in psoriatic epidermis. $\mathcal{F}$ Clin Invest 1992; 89. 1892-901.

29 Jankowski J, Austin W, Howat K, Coghill G, Hopwood D, Dover $\mathrm{R}$, et al. Proliferating cell nuclear antigen in oesophageal mucosa with autoradiography. Eur $\mathscr{f}$ Gastroenterol Hepatol 1992; 4: 579-84.

30 Squier CA, Hill MW. Oral mucosa. In: Ten Cate A, ed. Oral histology; development, structure and function. St Louis: CV Mosby, 1980: 340-89.

31 Dobson H, Hopwood D, D'Arrigo C. Role of integrins in the oesophagus. Gut 1993; 34: S9.

32 Sanders DSA, Stocks SC, Milner DM, Milner GA Hopwood D, Kerr MA. Membranous expression of carcinoembryonic antigen (CEA) in the normal cervical squamous mucosa. $\mathcal{F}$ Pathol 1992; 167: 77-82.

33 Inoue $M$, Ogawa $H$, Miyata $M$, Shiozaki $H$, Tanizawa $O$. Expression of E-cadherin in normal, benign and malig- nant tissues of female genital organs. Am $\mathcal{f}$ Clin Pathol 1992; 98: 76-80.

34 Kemler R. Classical cadherins. Seminars in Cell Biology 1992; 3: 149-55.

35 Wheelock MJ, Knudsen KA. Cadherins and associated proteins. In Vivo 1991; 5: 505-13.

36 Wayner EA, Carter WG, Piotrowicz RS, Kunicki TJ. The function of multiple extracellular matrix receptors in mediating cell adhesion to extracellular matrix: preparamediating cell tion of monoclonal antibodies to the fibronectin receptor that specifically inhibit cell adhesion to fibronectin and reacts with plate

37 Davies J, Warwick J, Totty N, Philp R, Helfrich M, Horton $M$. The osteoclast functional antigen, implicated in the regulation of bone resorption, is biochemically related to the vitronectin receptor. F Cell Biol 1989; 109: 1817-26.

38 De Strooper B, Saison M, Jaspers M. Monoclonal antibody DH 12 reacs with a cell surface and a presursor form of the $\beta$ subunit of the human fibronectin receptor. Cell Biol Int Rep 1988; 12: 9 .

39 Kennel SJ, Foote LJ, Falcioni R, Sonnenberg A, Stringer $\mathrm{CD}$, Crouse $\mathrm{C}$, et al. Analysis of the tumour-associated antigen TSP-180. Identity with $\alpha 6 \beta 4$ in the integrin antigen TSP-180. Identity with $\alpha 6 \beta 4$ in the
superfamily. F Biol Chem 1989; 15: $15515-21$.

40 Ramaswamy H, Hemler ME. Cloning, primary structure and properties of a novel human integrin $\beta$ subunit. EMBO 1990, 9: 1561-8.

41 Richman PI, Bodmer WF. Monoclonal antibodies to human colorectal epithelium: markers for differentiation and tumour characterization. Int $\mathcal{f}$ Cancer 1987; 39: 317-28.

42 Shimoyama $Y$, Hirohashi $S$, Hirano $S$, Noguchi $M$, Shimosato Y, Takeichi $M$, et al. Cadherin cell-adhesion molecules in human epithelial tissues and carcinomas. Cancer Res 1989; 49: 2128-33. 